\title{
Design of a high-specific speed turbine with non-uniform blade cascade
}

\author{
Jakub Stareček ${ }^{1, *}$, Pavel Čupr ${ }^{1}$, and Miloslav Haluza ${ }^{1}$ \\ ${ }^{1}$ Brno University of Technology, Faculty of Mechanical Engineering, Technická 2896/2, 616 69 Brno, Czech Republic
}

\begin{abstract}
This paper presents the hydraulic design of Kaplan type turbine in fully axial configuration. The turbine model consists of a straight pipe intake, a rib which covers the shaft, five axial guide vanes, a six blade runner and a $10,6^{\circ}$-full angle draft tube. Due to the presence of non-uniform velocity field behind the rib and interaction between stator and rotor, the pressure pulsations occur and cause some excitation forces acting on the runner. To reduce these negative phenomena the six non-uniform blade runner has been designed using computational fluid dynamics modelling (CFD). The runner blades are placed in various axial distances from the guide vanes. This new design should reduce the pressure pulsations caused by interaction between the rib and the runner, which is the main negative effect by the current design. The forces and torque which are acting on the runner blades as well as the pressure inside the turbine are observed in time domain. The amplitudes and frequencies are analysed using Fast Fourier Transform (FFT). The frequencies are compared to the modal analysis results of the runner submerged in water. This hydraulic design is based on previous axial turbine, which was designed for small hydro power plant located at Lužnice River. The design point is defined by head $\mathrm{H}=1,5 \mathrm{~m}$, volumetric flow rate $\mathrm{Q}=2,1 \mathrm{~m}^{3} / \mathrm{s}$ and $\mathrm{RPM} \mathrm{n}=260 \mathrm{~min}^{-1}$. This turbine was designed using six runner blades to reduce the pressure, force and torque pulsations caused mainly by wakes, which were observed behind the rib.
\end{abstract}

\section{Introduction}

The small hydropower plant Lužnice, which is located close to the city Tábor, contains six Kaplan turbines without any regulating mechanism. Each machine provides approximately performance of $P_{\text {out }}=16 \mathrm{~kW}$, which corresponds to the volumetric flow rate of $Q_{v}=1.5 \mathrm{~m}^{3} \cdot \mathrm{s}^{-1}$. It was decided to increase the output of the turbine during the rehabilitation of the first machine, which was reached by increasing of the volumetric flow rate to $Q_{v}=2.1 \mathrm{~m}^{3} \cdot \mathrm{s}^{-1}$. The parameters of the design point for the new turbine are: total head $H=1.5 \mathrm{~m}$, volumetric flow rate $Q_{v}=2.1 \mathrm{~m}^{3} \cdot \mathrm{s}^{-1}$ and RPM $n=260 \mathrm{~min}^{-1}$.

Each of the original turbines consisted of circular pipe which covered the shaft, nine guide vanes, four runner blades and $10.6^{\circ}$ full angle draft tube. The turbine runner had a diameter of $D=800 \mathrm{~mm}$ and the hub had a diameter of $d=272 \mathrm{~mm}$. As a part of the new design, the pipe which covered the shaft was replaced by a rib. The new design contains five guide vanes and six runner blades with lower wrap angle and higher efficiency. According to the CFD results, the output of the new designed turbine is ca. $P_{\text {out }}=25 \mathrm{~kW}$ and the hydraulic efficiency of the whole turbine is more than $\eta_{h}=84 \%$. The amplitudefrequency characteristics of static pressures, forces and torques were monitored during transient analysis and compared to the results of the modal analysis of the runner mounted on the shaft to avoid the resonance. After finishing the project, we decided to study the influence of blade position in axial direction on the pressure pulsations. This was realized by offsetting of every other blade of the runner in axial direction. The three turbine runners were designed using various offsets $(20 \mathrm{~mm}$, $40 \mathrm{~mm}$ and their combination). The last design was created by combination of all offsets, i.e. $0 \mathrm{~mm}, 20 \mathrm{~mm}$ and $40 \mathrm{~mm}$. This blade offset had a major impact on the excitation frequencies and their amplitudes. The changes in output parameters of the turbine especially in hydraulic efficiency were not noticed. This article describes the design process of the new turbine using numerical simulations and presents the results of amplitudefrequency characteristics for all cases.

\section{Hydraulic Design of the Turbine}

The specific speed of the new turbine calculated by (1) has a value of $n_{q}=278 \mathrm{~min}^{-1}$. The specific speed can be calculated by following equation:

$$
n_{q}=333 \cdot n \frac{\sqrt{Q_{v}}}{\sqrt[4]{Y^{3}}}
$$

where $Q_{v}\left[\mathrm{~m}^{3} \cdot \mathrm{s}^{-1}\right]$ is the volumetric flow rate, $Y[\mathrm{~J} \cdot \mathrm{Kg}]$ is the specific energy and $n\left[\mathrm{~min}^{-1}\right]$ is RPM. The unit RPM $n_{11}\left[\mathrm{~min}^{-1}\right]$ and unit flow rate $Q_{11}\left[\mathrm{~m}^{3} \cdot \mathrm{s}^{-1}\right]$ can be calculated using equations (2) and (3) which are based on the theory of hydraulic similarity. In this equations $H[\mathrm{~m}]$ is a head of water, $D[\mathrm{~m}]$ is a runner diameter.

$$
\begin{gathered}
n_{11}=\frac{n \cdot D}{\sqrt{H}} \\
Q_{11}=\frac{Q_{v}}{D^{2} \cdot \sqrt{H}}
\end{gathered}
$$

The preliminary design considered the use of the swirl turbine without guide vanes. The velocity triangles were used for the beta angle estimation. The assumption of straight intake on the blade without circumferential component of absolute velocity $c_{u l}\left[\mathrm{~m} \cdot \mathrm{s}^{-1}\right]$ was used at the leading edge of the blade. Meridional velocity component was calculated from continuity equation, circumferential component of absolute velocity $c_{u 2}\left[\mathrm{~m} \cdot \mathrm{s}^{-1}\right]$ was obtained from Euler's turbine equation (4) with hydraulic efficiency estimation and circumferential velocity $u_{1 / 2}\left[m \cdot s^{-1}\right]$ was based on RPM. 


$$
\text { g.H. } \eta_{h}=u_{1} c_{u 1}-u_{2} c_{u 2}
$$

The angle beta $\beta$ [deg] distribution along the blade length was linear. This beta angle distribution is often referred to as an energy-efficient solution. [3][4] Meridian length $L[\mathrm{~mm}]$ of a blade was estimated by $L=0.1 \cdot \mathrm{D}$ and was optimized during the design process considering the length and shape of the blade. Regarding to the presence of force pulsations and static pressure pulsations in the turbine chamber, the runner with six blades was chosen. The central line of the blade profile was characterised by beta angle distribution with inlet and outlet angle. At this central line the blade profile was applied. The NACA profile (National Advisory Committee for Aeronautics) from fourth series was used. The maximum thickness $t=27 \mathrm{~mm}$ was placed at $40 \%$ of the blade length at the hub, and $t=17 \mathrm{~mm}$ at the chamber. The gap was created between the blade and the turbine chamber with dimension of $t_{g}=1 \mathrm{~mm}$.

The first results of numerical CFD simulation predicted a backflow area in the draft tube and insufficient velocity field. The outlet blade angle at outer streamlines was too huge. The guide vanes were added in front of the runner to improve the velocity field and to reduce the backflow area. The presence of guide vanes allowed us to decrease the outlet blade angle by turning the runner. The maximum beta angle at guide vanes trailing edge was set to $\beta_{g 2}=27-35 \mathrm{deg}$ (from chamber to hub).

During the design process of the new turbine was also necessary to modify the inlet and outlet cone (hub) and the rib which covers the shaft. The current existing concrete draft tube with $10.6^{\circ}$ full angle opening was used from the original turbine (Fig. 1).

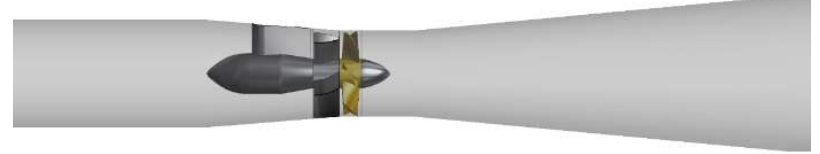

Fig. 1 The hydraulic model of a new turbine

\subsection{Monitored parameters}

Many various cases of geometry were designed before the parameters of the design point were met. These cases were compared to each other. The main criteria were performance, volumetric flow rate, hydraulic efficiency, static pressure pulsations in various points and forces pulsations. The hydraulic performance $P_{\text {out }}[W]$ was calculated by

$$
P_{\text {out }}=M_{k} \cdot \omega
$$

where $\omega\left[\mathrm{rad} \cdot \mathrm{s}^{-1}\right]$ is the angular velocity and $M_{k}[N \cdot \mathrm{m}]$ is the torque. Instantaneous torque was monitored during the transient simulation on the surface of the runner blades. The hydraulic efficiency was calculated as ratio between the hydraulic performance and the hydraulic input, which is given by

$$
P_{\text {in }}=Q_{v} \cdot \Delta p
$$

where $\Delta p[\mathrm{~Pa}]$ is the total pressure difference between the turbine inlet and the draft tube outlet. $Q_{v}\left[\mathrm{~m}^{3} \cdot \mathrm{s}^{-1}\right]$ represents the volumetric flow rate which is monitored at the draft tube outlet. The hydraulic efficiency $\eta_{h}[-]$ was evaluated using equation (7).[3][4]

$$
\eta_{h}=\frac{P_{\text {out }}}{P_{\text {in }}}
$$

Various quantities were monitored during the transient analysis to capture all excitation forces acting on the mechanical parts of the turbine, i. e. static pressure, forces and torques. The corresponding amplitude-frequency characteristics were obtained by Fast Fourier Transformation (FFT). The overview of all points, which were used to monitor the static pressure, is shown in the following picture (Fig. 2). The forces and torque were evaluated on the surface of the runner blades and guide vanes. The duration of the transient simulation was set to 4096 iterations, which corresponded to more than 22 revolutions of the runner.

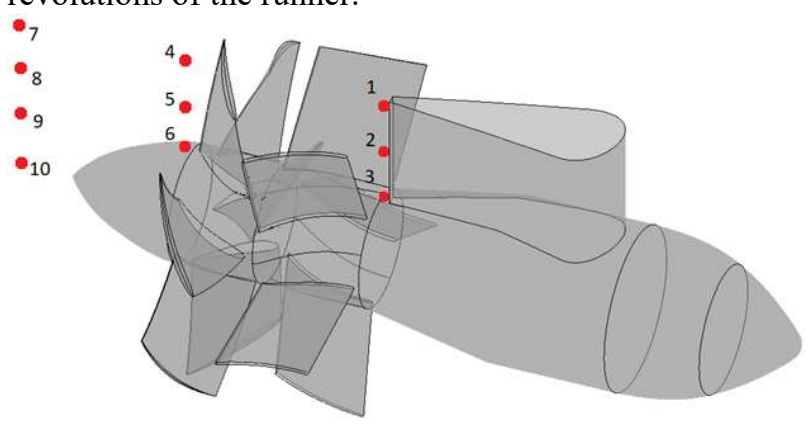

Fig. 2 Points used for evaluation of static pressure

\subsection{Design of runner with offset blades}

As a next step, the influence of blade position in axial direction was studied. Three configurations of runner blades were designed. The offset was realized by displacement of meridian blade cut in axial direction. The first and second configuration were created by displacement of every other blade. All the blades with modified position were moved by $20 \mathrm{~mm}$ in the first case and $40 \mathrm{~mm}$ in the second case (Fig. 4).

The last configuration was designed as a combination of various values of blade displacement. The first blade had a position of $0 \mathrm{~mm}$, the second one was moved by $20 \mathrm{~mm}$ and third was moved by $40 \mathrm{~mm}$. (Fig. 3)[1][2]

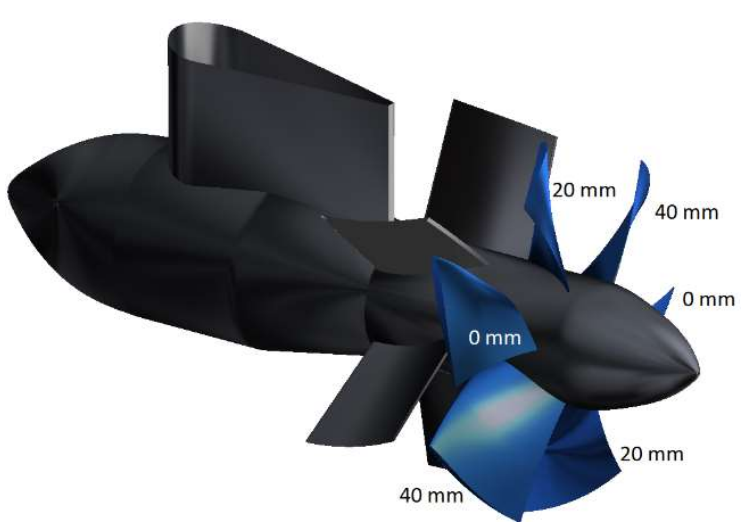

Fig. 3 The impeller with various offsets of blades 


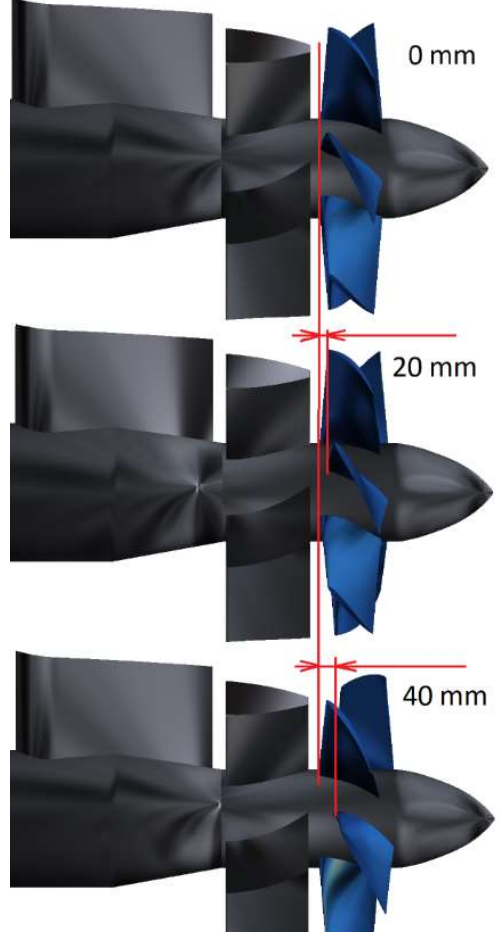

Fig. 4 The various offset of blades

\section{Numerical Simulation}

\subsection{Transient CFD analysis}

The runner and guide vanes were modelled separately using ANSYS BladeGen. The computational mesh was created using ANSYS Turbogrid and ICEM CFD. The volumetric losses were taken into account and therefore the blade gap between the runner and chamber was included in the model. The computational model of the whole turbine consisted of 6040000 hexahedral cells (6 274000 nodes). The mesh was created as structured with boundary layer refinements in the boundary layer.
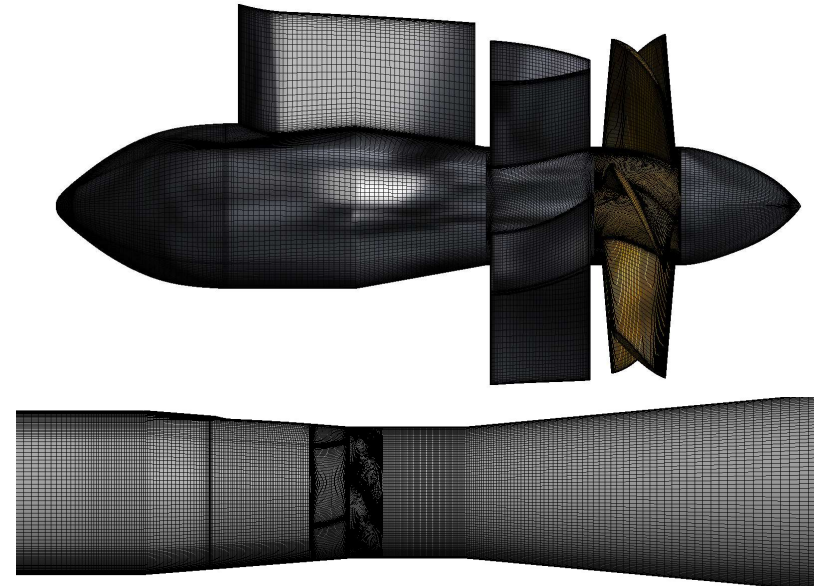

Fig. 5 Flow analysis - computational mesh

All simulations were calculated as transient analysis using ANSYS CFX. The time-step was defined to turn $2^{\circ}$ per time step, i. e. for $R P M n=260 \mathrm{~min}^{-1}$ was used time step $\Delta t=0.001282 \mathrm{~s}$ with six internal iterations. The analysis was carried out using $\mathrm{k}-\varepsilon$ realizable turbulence model. All parts were set as stationary with the exception of the runner. The transient ROTOR-STATOR interface (marked by green colour in the figure (Fig. 6)) was applied between rotating and stationary domain. The general grid interface - GGI was applied between the inlet domain and domain with guide vanes (marked by yellow colour) as well as between non-periodic blade-channels in the runner (purple marked). These interfaces enabled to connect the computational meshes with different mesh distributions at the common face. The no-slip wall boundary condition was applied on all faces where fluid can't flow through. The counter rotating wall was applied on the chamber in runner rotating domain. The total pressure boundary condition $\left(P_{t o t}=15000 \mathrm{~Pa}\right)$ was applied at the inlet (marked by blue colour) to simulate a head of water over the turbine. The zero static pressure $\left(P_{s}=0 \mathrm{~Pa}\right)$ was applied at the outlet of the domain (marked by red colour). The reference pressure was set to $P_{\text {ref }}=1 \mathrm{~atm}$.

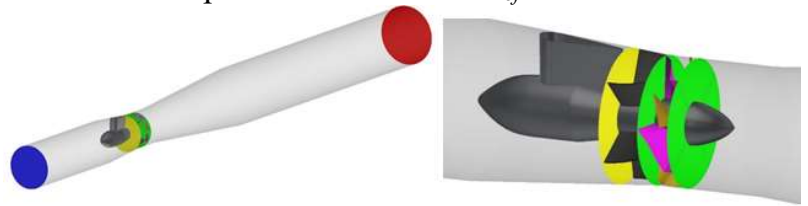

Fig. 6 Boundary conditions overview

The transient analyses were carried out for various RPM, i. e. $n_{1}=160 \mathrm{~min}^{-1}, n_{2}=210 \mathrm{~min}^{-1}, n_{3}=260 \mathrm{~min}^{-1}$ and $n_{4}=310 \mathrm{~min}^{-1}$, to observe the influence on output characteristics.

\subsection{Acoustic modal analysis}

The acoustic modal analysis was carried out to ensure that there is no coincidence between the excitation frequencies coming from the flow and natural frequencies of the runner mounted on the shaft. When the runner is submerged in water its modal properties are influenced by added mass effect. The computational model consisted of the runner and shaft fixed in bearings and an acoustic domain representing the water around the runner. The material properties of linear elastic material model which was used for structural parts are in Table 1. The runner was made of chrome-nickel steel and the shaft was made of construct steel (class 12).

Table 1 Structural and fluid material properties

\begin{tabular}{|c|c|c|}
\hline Material & $\begin{array}{c}\text { Chrome - } \\
\text { nickel steel }\end{array}$ & Construct steel \\
\hline Density $\left[\mathrm{Kg} / \mathrm{m}^{3}\right]$ & 7700 & 7800 \\
\hline Young modulus [MPa] & 206000 & 210000 \\
\hline Poisson ratio [-] & 0.288 & 0.33 \\
\hline & Density & Speed of sound \\
\hline Water & $998.2 \mathrm{~kg} / \mathrm{m}^{3}$ & $1482.1 \mathrm{~m} / \mathrm{s}$ \\
\hline
\end{tabular}

The water was represented by acoustic elements. The computational mesh was created in ANSYS Meshing using 590000 linear hexahedral and tetrahedral elements (354000 nodes). For material properties of water see Table 1. The computational mesh is shown in the figure below (Fig. 7). 


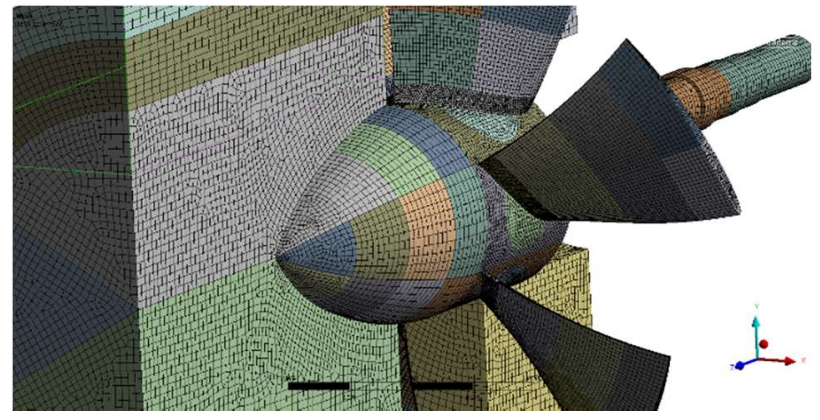

Fig. 7 Acoustic modal analysis - computational mesh

The shaft, fully connected to the runner, was fixed in the bearings by displacement boundary conditions. All degrees of freedom were fixed except the rotation around shaft axis. The FSI interface was applied on the surface where the hub and runner are in contact with water. The zero acoustic pressure was applied at the inlet and outlet of the domain.

The first six natural frequencies of the runner submerged in still water are shown in the table below.

Table 2 Natural frequencies of runner submerged in water

\begin{tabular}{|c|c|}
\hline Mode & fwater $[\mathrm{Hz}]$ \\
\hline 1 & 0 \\
\hline 2 & 57.833 \\
\hline 3 & 134.36 \\
\hline 4 & 149.61 \\
\hline 5 & 187.62 \\
\hline 6 & 347.53 \\
\hline
\end{tabular}

\section{Results}

The unit RPM and unit flow rate were calculated using equations (2) and (3) to compare the $n_{11}-Q_{11}$ characteristics for all three configurations to the original one (Fig. 8).

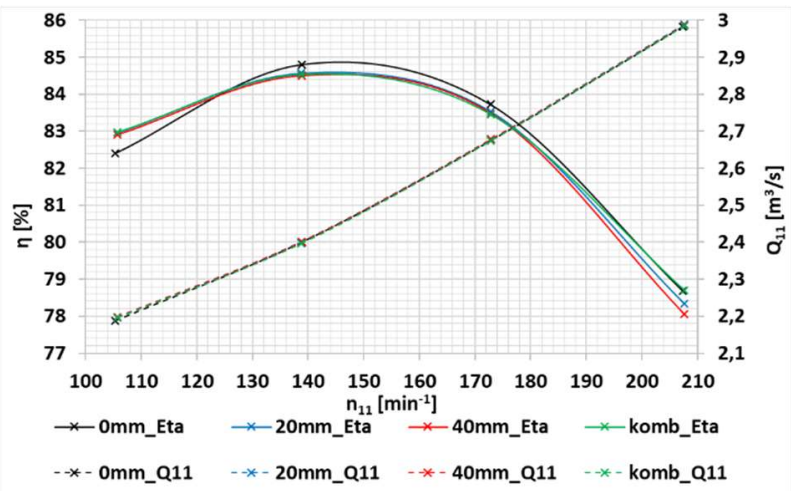

Fig. 8 Comparison of $\mathrm{n}_{11}-\mathrm{Q}_{11}$ characteristics for all configurations

The $n_{11}-Q_{11}$ characteristics show, that a small blade displacement (compared to the runner dimensions) has no major impact on the flow characteristics. A light drop of hydraulic efficiency is significant, but it does not exceed more than one percent. The performance characteristics of all configurations correspond to the original one with maximum difference of $0.5 \%$ (Fig. 9).

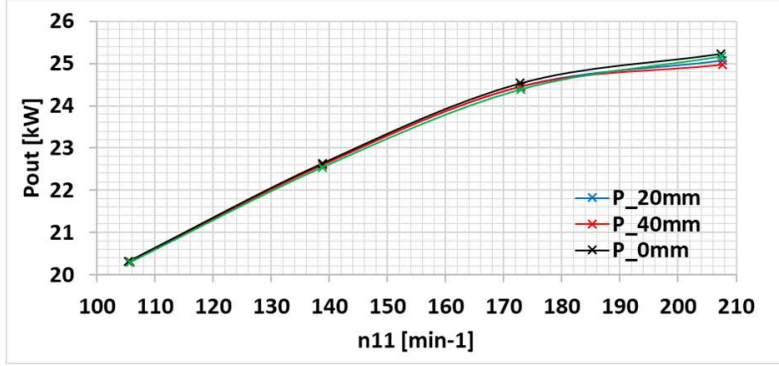

Fig. 9 Performance characteristics

The amplitude-frequency characteristics were evaluated from the monitored variables. The dominant detected frequencies for the original turbine are summarized in Table 3. The rotational frequency $f_{r}[\mathrm{~Hz}]$ was calculated from RPM. The blade frequency $f_{b}[\mathrm{~Hz}]$ is dominant and corresponds to the blades passing around the guide vane or monitor point.

These pressure pulsations observed behind the runner are mainly caused by non-uniform fields of flow and pressure behind the trailing edges of the runner blades. The non-uniform velocity field is characterized by periodic changes of the circumferential component of absolute velocity $c_{u 2}$. These instabilities can be also observed in the draft tube, but their amplitudes are damped.

The pressure pulsations which were detected behind the rib and also on the guide vane surface are mainly caused by propagation of pressure pulsations in the liquid. In this case, the pressure pulsations are generated by periodic motion of the runner blades around the stationary parts of the turbine.

Table 3 Frequencies detected in original configuration

\begin{tabular}{|l|l|l|}
\hline Rotational frequency & & $\mathbf{4 . 3 3 ~ H z}$ \\
\hline Blade frequency & $6 \times 4.33 \mathrm{~Hz}$ & $\approx \mathbf{2 6 ~ H z}$ \\
\hline
\end{tabular}

\subsection{Observed excitation frequencies}

All presented results correspond to the RPM value of $n_{3}=260 \mathrm{~min}^{-1}$.

\subsubsection{Pulsations in the impeller domain}

The pressure pulsations were monitored in various points (Fig. 2). The most significant impact of the blade offset on the static pressure pulsations was observed at the outlet of the impeller domain (points P4, P5 and P6 in Fig. 2). The maximum detected amplitudes and the corresponding frequencies are summarized in Table 4. Each column in the table shows the maximum detected amplitudes plotted in one of the figures below (P4 - Fig. 10, P5 -

Fig. 11 and P6 - Fig. 12).

The highest amplitude decrease (28\%-45\%) was obtained for the configuration with blade offset $20 \mathrm{~mm}$. While the distance from the hub in radial direction is increasing, the amplitude drop is decreasing. The highest amplitude drop was observed in point P6, which is located close to the hub. The amplitude drop was also observed for the configurations with various blade offsets $(16 \%-20 \%)$ and $40 \mathrm{~mm}$ offset $(10 \%-11 \%)$. 


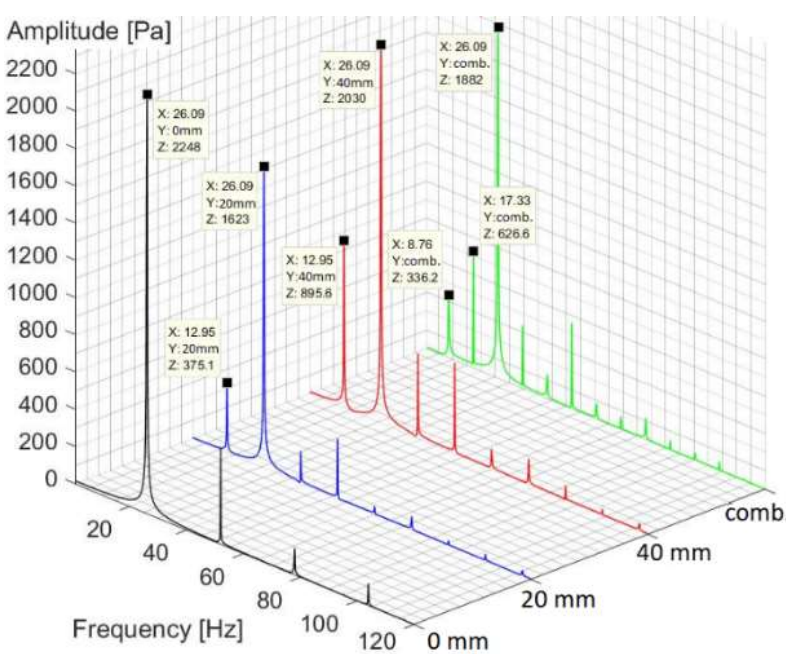

Fig. 10 Amplitude-frequency characteristics calculated from point 4 for static pressure (at $90 \%$ height of turbine chamber)

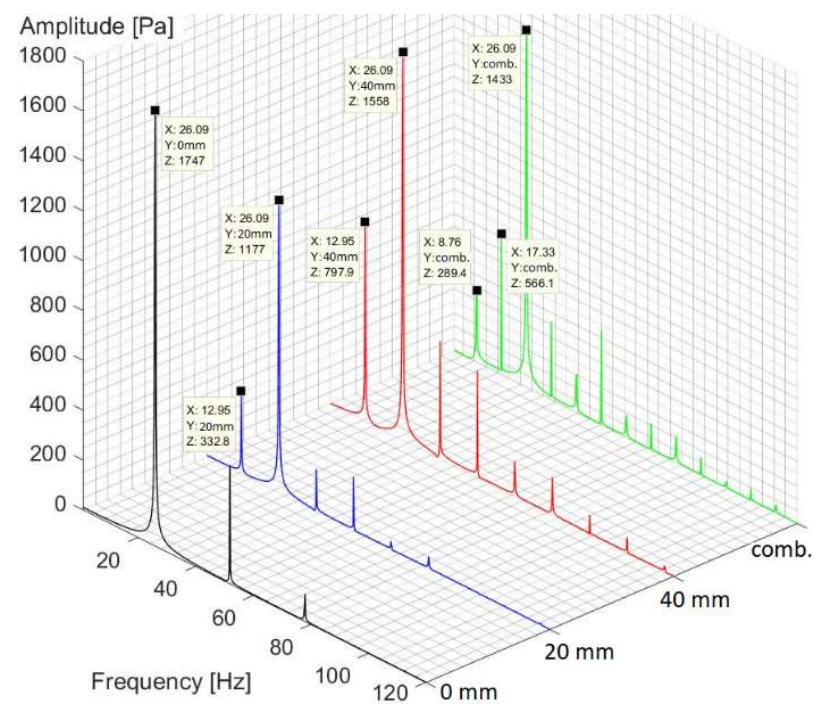

Fig. 11 Amplitude-frequency characteristics calculated from point 5 for static pressure (at $50 \%$ height of turbine chamber)

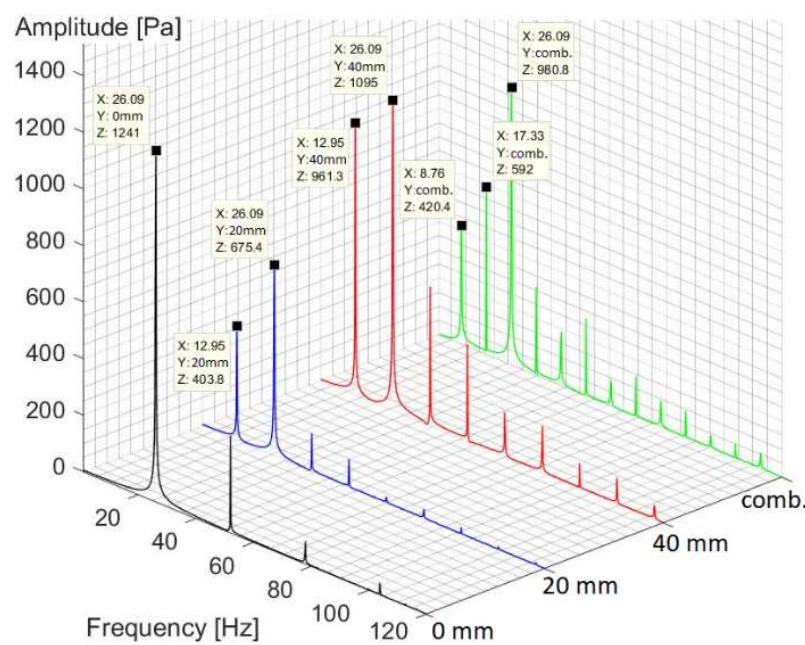

Fig. 12 Amplitude-frequency characteristics calculated from point 6 for static pressure (at $10 \%$ height of turbine chamber)
Table 4 The overview of maximum static pressure amplitudes behind the runner

\begin{tabular}{|c|c|c|c|c|}
\hline \multicolumn{5}{|c|}{ Pressure amplitudes $[\mathrm{Pa}]$ and corresponding freq. $[\mathrm{Hz}]$} \\
\hline \multirow{2}{*}{$\begin{array}{l}\text { Offset } \\
{[\mathrm{mm}]}\end{array}$} & \multicolumn{4}{|c|}{ Monitor point } \\
\hline & \multicolumn{2}{|l|}{ P4 } & \multicolumn{2}{|l|}{ P5 } \\
\hline 0 & $2250[26 \mathrm{~Hz}]$ & $0 \%$ & $1750[26 \mathrm{~Hz}]$ & $0 \%$ \\
\hline 20 & $1620[26 \mathrm{~Hz}]$ & $-28 \%$ & $1180[26 \mathrm{~Hz}]$ & $-33 \%$ \\
\hline 40 & $2030[26 \mathrm{~Hz}]$ & $-10 \%$ & $1560[26 \mathrm{~Hz}]$ & $-11 \%$ \\
\hline Comb. & $1880[26 \mathrm{~Hz}]$ & $-16 \%$ & $1440[26 \mathrm{~Hz}]$ & $-18 \%$ \\
\hline \multirow{2}{*}{$\begin{array}{l}\text { Offset } \\
{[\mathrm{mm}]}\end{array}$} & \multicolumn{4}{|c|}{ Monitor point } \\
\hline & \multicolumn{2}{|l|}{ P6 } & & \\
\hline 0 & $1240[26 \mathrm{~Hz}]$ & $0 \%$ & & \\
\hline 20 & $680[26 \mathrm{~Hz}]$ & $-45 \%$ & & \\
\hline 40 & $1100[26 \mathrm{~Hz}]$ & $-11 \%$ & & \\
\hline Comb. & $980[26 \mathrm{~Hz}]$ & $-20 \%$ & & \\
\hline
\end{tabular}

\subsubsection{Pulsations behind the rib}

The offset of runner blades has also positive impact on the amplitudes of static pressure pulsations evaluated near the trailing edge of the rib (points $\mathrm{P} 1-\mathrm{P} 3$ in Fig. 2). The maximum detected amplitudes and the corresponding frequencies are summarized in Table 5.

The highest amplitude drop was reached by configuration with various blade offsets (24\%-32\%). Compared to the original design without blade offset, the excitation frequency $8.8 \mathrm{~Hz}$ occurred. The significant amplitude decrease $(15 \%-16 \%)$ was also observed by configuration with $20 \mathrm{~mm}$ blade offset. The amplitudefrequency characteristics evaluated in point P2. that is located in the centre of flow channel behind the rib, are shown in the figure below (Fig. 13).

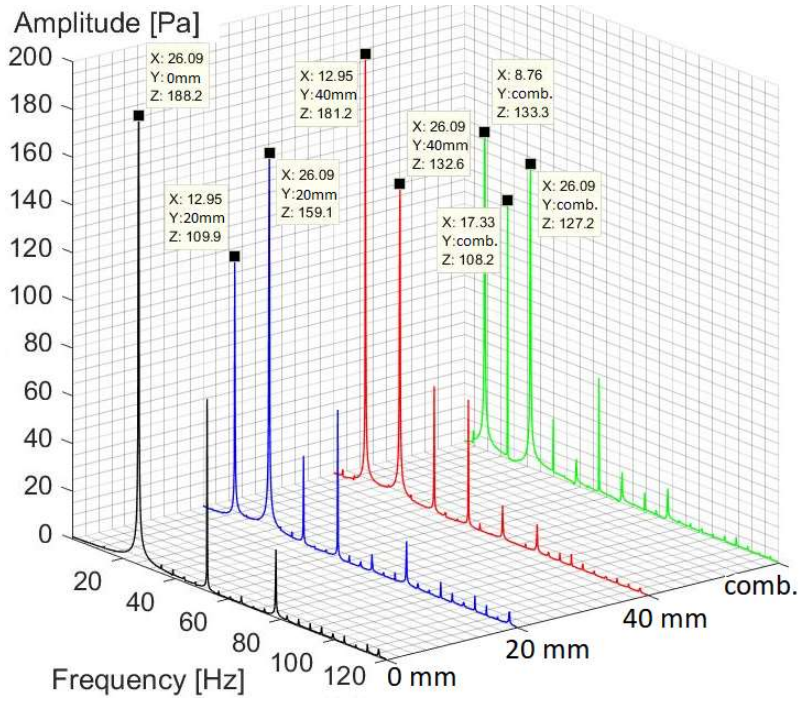

Fig. 13 Amplitude-frequency characteristics calculated from point 2 for static pressure (behind the rib at centre streamline) 
Table 5 The overview of maximum static pressure amplitudes behind the rib

\begin{tabular}{|c|c|c|c|c|}
\hline \multicolumn{5}{|c|}{ Pressure amplitudes [Pa] and corresponding freq. [Hz] } \\
\hline $\begin{array}{c}\text { Offset } \\
{[\mathrm{mm}]}\end{array}$ & \multicolumn{5}{|c|}{$\mathrm{P} 1$} & \multicolumn{2}{c|}{$\mathrm{P} 2$} \\
\hline 0 & $186[26 \mathrm{~Hz}]$ & $0 \%$ & $188[26 \mathrm{~Hz}]$ & $0 \%$ \\
\hline 20 & $156[26 \mathrm{~Hz}]$ & $-16 \%$ & $159[13 \mathrm{~Hz}]$ & $-15 \%$ \\
\hline 40 & $211[13 \mathrm{~Hz}]$ & $+13 \%$ & $181[13 \mathrm{~Hz}]$ & $-4 \%$ \\
\hline Comb. & $141[8.8 \mathrm{~Hz}]$ & $-24 \%$ & $128[8.8 \mathrm{~Hz}]$ & $-32 \%$ \\
\hline $\begin{array}{c}|c| \\
\text { Offset } \\
{[\mathrm{mm}]}\end{array}$ & $\mathrm{P} 3$ & & & \\
\hline 0 & $168[26 \mathrm{~Hz}]$ & $0 \%$ & & \\
\hline 20 & $142[26 \mathrm{~Hz}]$ & $-15 \%$ & & \\
\hline 40 & $152[13 \mathrm{~Hz}]$ & $-10 \%$ & & \\
\hline Comb. & $116[8.8 \mathrm{~Hz}]$ & $-31 \%$ & & \\
\hline
\end{tabular}

\subsubsection{Pulsations in the draft tube}

The draft tube is the only part of the turbine where the impact of blade offset on the static pressure pulsations was slightly negative (see Table 6).

The amplitudes of pressure pulsations in point P10 located near the wall rapidly increased up to $+471 \%$. The excitation frequencies observed in this point are multiples of blade frequencies. All maximum amplitudes in the draft tube are in the orders of Pascal and their impact on the dynamic behaviour of the turbine is negligible.

Table 6 The overview of maximum static pressure amplitudes in the draft tube

\begin{tabular}{|c|c|c|c|c|}
\hline Pressure amplitudes [Pa] and corresponding freq. [Hz] \\
\hline \multirow{2}{*}{$\begin{array}{c}\text { Offset } \\
{[\mathrm{mm}]}\end{array}$} & \multicolumn{4}{|c|}{ Monitor point } \\
\cline { 2 - 5 } & \multicolumn{2}{|c|}{$\mathrm{P} 7$} & \multicolumn{2}{c|}{$\mathrm{P} 8$} \\
\hline 0 & $33[26 \mathrm{~Hz}]$ & $0 \%$ & $43[26 \mathrm{~Hz}]$ & $0 \%$ \\
\hline 20 & $19[62 \mathrm{~Hz}]$ & $-42 \%$ & $41[26 \mathrm{~Hz}]$ & $-5 \%$ \\
\hline 40 & $32[62 \mathrm{~Hz}]$ & $-3 \%$ & $42[26 \mathrm{~Hz}]$ & $-2 \%$ \\
\hline Comb. & $42[17.3 \mathrm{~Hz}]$ & $+27 \%$ & $38[26 \mathrm{~Hz}]$ & $-11 \%$ \\
\hline Offset & \multicolumn{5}{|c|}{ Monitor point } \\
\cline { 2 - 5 }$[\mathrm{mm}]$ & $\mathrm{P} 9$ & $\mathrm{P} 10$ \\
\hline 0 & $26[26 \mathrm{~Hz}]$ & $0 \%$ & $14[26 \mathrm{~Hz}]$ & $0 \%$ \\
\hline 20 & $22[26 \mathrm{~Hz}]$ & $-15 \%$ & $77[13 \mathrm{~Hz}]$ & $+450 \%$ \\
\hline 40 & $25[39 \mathrm{~Hz}]$ & $-4 \%$ & $60[13 \mathrm{~Hz}]$ & $+328 \%$ \\
\hline Comb. & $20[52 \mathrm{~Hz}]$ & $-23 \%$ & $80[8.8 \mathrm{~Hz}]$ & $+471 \%$ \\
\hline
\end{tabular}

\subsubsection{Forces acting on the stator blade}

The offset of runner blades has major impact on the forces acting on the guide vane surface. The increase of force amplitudes between $10 \%-80 \%$ is observed by the offsets of $20 \mathrm{~mm}$ and $40 \mathrm{~mm}$ (Table 7). The slight decrease of force amplitude (-9\%) was observed by the configuration with various blade offsets (Fig. 14). All detected frequencies are multiples of the blade frequency $(26 \mathrm{~Hz})$.

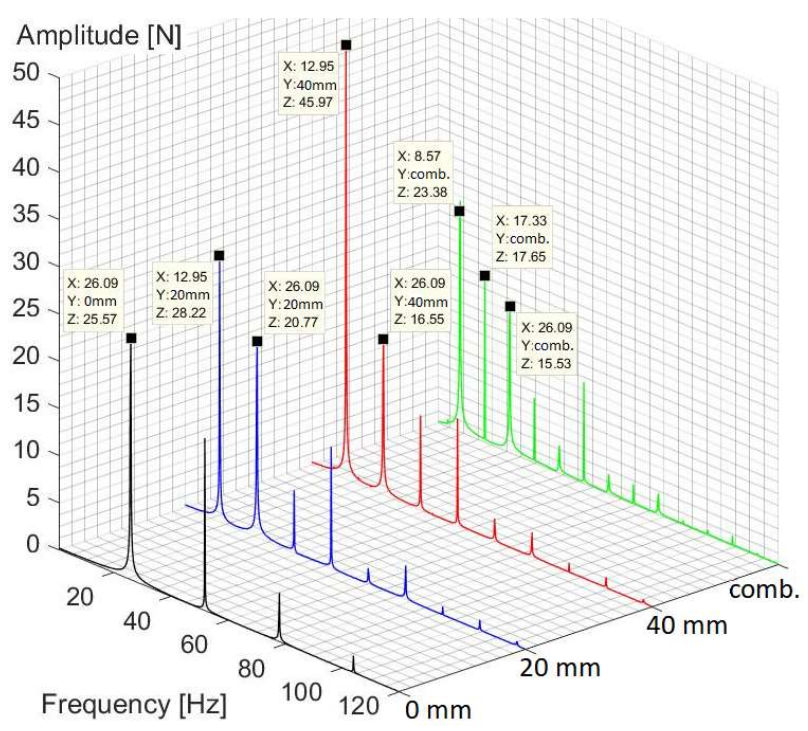

Fig. 14 Amplitude-frequency characteristics calculated from force acting on the stator blade

Table 7 The overview of maximum force amplitudes acting on the guide vane

\begin{tabular}{|c|c|c|l|l|}
\hline \multicolumn{5}{|c|}{ Force amplitudes [N] and corresponding freq. [Hz] } \\
\hline $\begin{array}{c}\text { Offset } \\
{[\mathrm{mm}]}\end{array}$ & Gonitor point \\
\hline & Guide vane & & \\
\hline 0 & $25.57[26 \mathrm{~Hz}]$ & $0 \%$ & & \\
\hline 20 & $28.2[13 \mathrm{~Hz}]$ & $+10 \%$ & & \\
\hline 40 & $46[13 \mathrm{~Hz}]$ & $+80 \%$ & & \\
\hline Comb. & $23.38[8.8 \mathrm{~Hz}]$ & $-9 \%$ & & \\
\hline
\end{tabular}

No significant impact of the blade offset on the amplitudes and frequencies calculated for the forces acting on the runner blades were detected.

The all excitation frequencies detected from all ten points P1 - P10 were compared to the results of acoustic modal analysis. No coincidence between the excitation frequencies and natural frequencies of runner submerged in water was found.

\section{Conclusion}

The influence of runner blade offset in axial direction on the static pressure pulsations was investigated. Three configurations of blade offset were designed. The offset was realized by displacement of meridian blade cut in axial direction. The first and second configuration were created by displacement of every other blade. All the blades with modified position were moved by $20 \mathrm{~mm}$ in the first case and by $40 \mathrm{~mm}$ in the second case. The last configuration was designed as a combination of various values of blade displacement.

The decrease of pressure amplitudes behind the rib and behind the runner was achieved by all three configurations. The performance characteristics of all configurations correspond to the original one with maximum difference of $0.5 \%$. The only increase of pressure amplitudes was observed near the wall of the draft tube. These pulsations have no significant effect on the machine dynamics, as the amplitudes are in orders of 
Pascal. The similar trend of pressure pulsations was also observed for different values of RPM, i. e. $n_{1}=160 \mathrm{~min}^{-1}, n_{2}=210 \mathrm{~min}^{-1}$ and $n_{4}=310 \mathrm{~min}^{-1}$.

The highest static pressure amplitude drop was reached by $20 \mathrm{~mm}$ blade offset in all parts of the turbine (15\%-16\% behind the rib, $28 \%-45 \%$ at the outlet of impeller domain and $15 \%-42 \%$ in the draft tube). The only negative effect of the blade offset for all configurations was observed near wall of the draft tube. The increase of pressure amplitudes was by all configurations in the range of $328 \%-471 \%$. The absolute value of these amplitudes are in orders of Pascal and have insignificant impact on the dynamic behaviour of the turbine.

The significant amplitude decrease was also observed by the configuration with various axial blade offset (24\%-32\% behind the rib, $16 \%-20 \%$ at the outlet of impeller domain).

The pressure amplitudes decreased by all offset configurations. Another important fact is, that new excitation frequency occurred. By the offset of $20 \mathrm{~mm}$ and $40 \mathrm{~mm}$, the new excitation frequency $13 \mathrm{~Hz}$ occurred. This frequency has a half value of the dominant frequency detected by the original runner without offset. By configuration with various blade offsets the new excitation frequencies $8.8 \mathrm{~Hz}$ and $17.3 \mathrm{~Hz}$ were detected.

The acoustic modal analysis was also carried out to ensure that there is no coincidence between the detected excitation forces and natural frequencies of the runner. This analysis enables to calculate natural frequencies and corresponding mode shapes for runner submerged in the water, which is more accurate. The first six natural frequencies were computed. These frequencies were compared to all excitation frequencies detected in the whole turbine and no coincidence was found.

The future steps will continue with the analysis of the runner with all six blades moved about $20 \mathrm{~mm}$.

This work has been supported by specific research project no. FSI-S-17-4615 "Multiphysics Problems in Fluid Mechanics".

\section{References}

1. J. Veselý, F. Pochylý, J. Obrovský, J. Mikulášek. A New Concept of Hydraulic Design of Water Turbine Runners. International Journal of Fluid Machinery and systems. Turbomachinery Society of Japan, Korean Fluid Machinery Association, Chinese Society of Engineering Thermophysics, IAHR, 383-391 (2009)

2. F. Pochylý, M. Haluza, J. Veselý, The Francis Pump Turbine With Stochastic Blades. Procedia Engineering. Elsevier, 68-75 (2012)

3. J. Bednáŕ, Turbiny: (malé vodni elektrárny). Češkovice: Marcela Bednářová, (357), (2013) ISBN-978-80-905437-0-6

4. M. Nechleba, Vodní turbíny, jejich konstrukce a př́slušenství. Praha: Státní nakladatelství, (539) (1962), ISBN-04-241-61 